BRE 12509

\title{
Changes in vasopressin cells of the rat suprachiasmatic nucleus with aging
}

\author{
B. Roozendaal, W.A. van Gool, D.F. Swaab, J.E. Hoogendijk and M. Mirmiran \\ Netherlands Institute for Brain Research, Amsterdam (The Netherlands)
}

(Accepted 9 September 1986)

Key words: Aging; Circadian rhythm; Enriched environment; Male rat; Morphometry; Suprachiasmatic nucleus; Vasopressin

\begin{abstract}
The suprachiasmatic nucleus ( $\mathrm{SCN}$ ) of the hypothalamus is considered to be the endogenous clock of the mammalian brain, regulating circadian rhythmicity of a great number of physiological and behavioural parameters. Numerous studies have shown that the circadian organization in the rat is progressively disturbed in senescence. However, a recent study by Peng et al. ${ }^{17}$ using conventionally stained material, revealed no decrease in overall SCN cell number of senescent rats. Their results have now been confirmed in this study. In addition, an increase in SCN volume $(P=0.02)$ and nucleus diameter $(P=0.001)$ and an overall decrease in cell density $(P=$ $0.006)$ was observed. All these parameters seem to confirm the absence of a general degeneration in the senescent SCN. However, the major aim of the present study was to determine whether a well-defined population of neurons, i.e. the vasopressinergic (AVP) cells of the $\mathrm{SCN}$, shows changes with aging. Immunocytochemical staining with antivasopressin and morphometry revealed a decrease of $31 \%$ $(P=0.007)$ in the number of these SCN neurons, whereas the remaining vasopressin cells became larger $(P=0.001)$. There were no statistical significant differences between rats housed in standard cages and those housed in an enriched environment in either age group, but the groups were relative small. Changes in either the number or stainability of SCN vasopressin neurons may be a morphological correlate of changed circadian rhythms in senescence.
\end{abstract}

\section{INTRODUCTION}

The suprachiasmatic nucleus (SCN) of the hypothalamus is considered to play an important role in mammalian circadian rhythms ${ }^{15,16,18}$. The circadian timekeeping system changes in old age, both in humans and in animals, as demonstrated by a reduced amplitude and period length of circadian rhythms and an increased tendency towards internal desynchronization (for reviews see refs. 1, 8, 14, 25). A possible morphologic substrate for the disturbed circadian rhythms during senescence might be the reduction in total cell number and arginine-vasopressin (AVP) neurons as recently described in elderly human subjects and patients with Alzheimer's disease $(\mathrm{AD})^{20}$. Total cell number in the rat $\mathrm{SCN}$, on the other hand, was shown not to change up to the age of 33 months ${ }^{17}$. This does, of course, not exclude the possibility that a decrease in the number of neurons is compensated for by an increase in the number of glial cells.

In the present study the SCN of young and old rats was studied morphometrically using both conventional (thionin) and immunocytochemical staining of the AVP neurons ${ }^{20}$. These studies were performed on rats in which sleep-wakefulness patterns had been documented in detail in a separate study ${ }^{26}$. The results of that study have clearly shown a significant decrease in amplitude of the circadian sleep-wake rhythm in old compared to young rats. This material allowed us to correlate morphological and functional parameters in individual young and old rats. During the sleep experiment young and old rats were housed in either standard or enriched conditions. Possible effects of this differential housing on the morphology of the SCN will therefore also be mentioned briefly in this report. 


\section{MATERIALS AND METHODS}

Young (7-8 months) and old (32-33 months) male Brown Norway (BNBiRij) rats obtained from the Institute of Experimental Gerontology (TNO-Rijswijk, The Netherlands) were used in this study. Half of the young $(n=10)$ and old $(n=10)$ rats were housed in groups of 3-5 in standard laboratory cages, containing only wood shavings. The remaining 10 young and 10 old rats were housed in an enriched environment during the $8-10$ weeks preceding the present study. The 'enriched' cages were located in the same room as the standard cages, but they were larger and, in addition, provided with various toys, ladders, ropes, plexiglas boxes and tubes. The 'enriched' rats were moved every day to another cage and the objects were rearranged every 4 days ${ }^{26}$. All rats had been implanted with an electrode socket to allow for sleep-wakefulness recordings and such recordings, lasting $24-48 \mathrm{~h}$, were made about one month prior to perfusion ${ }^{26}$.

Rats $(n=40)$ were anaesthetized with sodium pentobarbital (Nembutal, $0.1 \mathrm{ml} / 100 \mathrm{~g} \mathrm{~b}$. wt.) and perfused intracardially with $0.9 \%$ saline, followed by a fixative consisting of $2.5 \%$ glutaraldehyde, $1 \%$ paraformaldehyde in $0.1 \mathrm{M}$ sodium cacodylate buffer, $\mathrm{pH}$ 7.4. Young and old rats were perfused in a random order within an interval of about $5 \mathrm{~h}$. The brain was submerged in the fixative and left overnight in the intact skull for postfixation. The next day the brain was removed from the skull and the hypothalamus was dissected. After another two weeks of fixation the hypothalamus was dehydrated and embedded in paraffin. Serial $6-\mu \mathrm{m}$ coronal sections were cut on a Leitz microtome and the sections were mounted on chrome-alum-coated slides. After dehydration, every tenth section was stained with a conventional (thionin) staining method. Hypothalami from 25 rats (6 young standard (YS), 5 young enriched (YE), 9 old standard (OS) and 5 old enriched $(\mathrm{OE}))$ were selected for further morphometric analysis. The remainder $(n=15)$ was discarded because of asymmetric sectioning, improper mounting or damage in the SCN area. From the time of perfusion all preparations were coded, thus all subsequent procedures and analyses were performed blindly.

\section{Morphometry}

Morphometric measurements were performed on a digitizer (Calcomp 2000) using a Zeiss microscope with $2.5 \times, 10 \times$ and $40 \times$ (Plan) objectives and $12.5 \times$ (Plan) oculars. Bilateral area measurements of the $\mathrm{SCN}$ were performed in the thionin-stained material using the $10 \times$ objective by measuring every tenth section in the SCN. At the rostral and caudal ends of the SCN every fifth section was analyzed, since the shape of the SCN changed rapidly in this area (cf. ref. 11). In this way $11 \pm 0.3$ (mean \pm S.E.M.) sections were measured in each rat. The cell density was not equal throughout the $\mathrm{SCN}$, the dorsomedial area contained more tightly packed cells, while the cell density was less in the dorsolateral part. In the latter region it was difficult to distinguish the SCN cells from the surrounding cells in the anterior hypothalamus. In analogy to Güldner ${ }^{6}$ and Van den $\mathrm{Pol}^{23}$ this area was therefore excluded from morphometric analysis in order to reduce the variability in the identification of the SCN.

The SCN volume was determined by integrating the area measurements ${ }^{22}$. The area measurement with the maximal value was described as a separate parameter, i.e. the maximal cross-sectional area.

Total cell density was determined by counting the nucleus profiles in a unit area at $500 \times$ magnification. Preliminary analysis taken from 7 rostral to caudal sections in one young and one old animal, did not reveal any gradient in cell density in the SCN. Therefore cell density measurements were restricted to the section with the maximal cross-sectional area at the right hand side. In each subject a minimum of 250 huclear profiles were measured in this section. By using an unfolding procedure, thus correcting for section thickness $(6 \mu \mathrm{m})$ and including the modification proposed by Cruz-Orive ${ }^{3}$, cell density, mean nucleus diameter and mean volume of the cell nuclei were calculated. This program was developed by R.W.H. Verwer in our institute. The total cell number at the right hand side was estimated by multiplying cell density with SCN volume in each individual case.

AVP cells were not randomly distributed within the SCN but were concentrated in the more dorsomedial part of the nucleus ${ }^{2,21}$. All the stained cell profiles were measured at $500 \times$ magnification in some 7 sections of equal distances throughout the SCN and unfolded, using the surface of the corresponding 
SCN in the adjacent thionin-stained sections to determine the size of the area. AVP cell density and cell diameter were determined using the same unfolding procedure as mentioned above. By multiplying AVP cell density with the SCN volume the AVP cell number was estimated. In order to judge the staining intensity the section with the maximal cross-sectional area was selected and AVP staining intensity in the SCN was estimated by two investigators. The sections were ranked from low to high intensity and tested for differences (cf. ref. 5).

In 20 cases the AVP staining was adequate for morphometric analysis. In the remaining 5 animals ( 3 young and 2 old) it was not possible to measure AVP neuron profiles because staining was absent. Two of these animals (one young and one old) were excluded from morphometrics, because the supraoptic nuclei (SON) were also not properly stained. The weak staining might be due to improper perfusion, fixation or staining procedures. Statistical analyses of AVP measurements were performed both with and without the remaining 3 weakly stained animals to test for the possible influence of deleting these animals from further analysis,

\section{Immunocytochemistry}

For immunocytochemical staining of the AVP-containing cells, the sections were hydrated and rinsed in TBS (Tris-buffered saline: $0.05 \%$ Tris, $0.9 \% \mathrm{NaCl}$, $\mathrm{pH} 7.6$ ) for $2 \times 10 \mathrm{~min}$. The sections were subsequently: (a) incubated with anti-AVP (Truus, 18-0985) $1: 800$ in $0.5 \%$ Triton $X-100$ in TBS overnight at $4{ }^{\circ} \mathrm{C}$; (b) washed in TBS $(2 \times 10 \mathrm{~min})$; (c) incubated with goat anti-rabbit serum (Betsy) 1:100 in TBS for $30 \mathrm{~min}$; (d) washed in TBS $(2 \times 10 \mathrm{~min})$; (e) incubated with peroxidase-antiperoxidase (PAP) 1:700 in TBS for $30 \mathrm{~min}$; (f) washed in TBS $10 \mathrm{~min}$; (g) preincubated with $0.05 \mathrm{M}$ Tris- $\mathrm{HCl} \mathrm{pH} 7.6$ (5 min); (h)

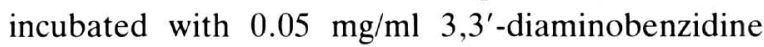
(DAB) (Sigma) in $0.05 \mathrm{M}$ Tris- $\mathrm{HCl} \mathrm{pH} 7.6$ containing $0.01 \% \mathrm{H}_{2} \mathrm{O}_{2}$ (Merck) for about $20 \mathrm{~min}$; (i) washed in aqua dest.; (j) dehydrated and mounted in Entellan.

\section{Statistics}

The Mann-Whitney $U$ (MW-U)-test (two-tailed, corrected for ties, 0.05 level of significance) was used to test differences. Differences between bilaterally determined parameters were calculated with the Wil- coxon matched-pairs ranked-signs test (two-tailed, 0.05 level of significance). Correlation coefficients were calculated using the Pearson rank correlation (0.05 level of significance).

\section{RESULTS}

None of the bilaterally determined parameters revealed a significant lateralization effect. The $P$-value of the difference between paired observations in the left and right nucleus was for the SCN volume, rostrocaudal axis (length) and maximal cross-sectional area $0.81,0.13$ and 0.98 , respectively. Therefore for further analysis, measurements of the left and right nucleus in individual rats were averaged (cf. Table I and II); the other morphometric parameters were determined only at the right hand side.

\section{Effects of housing environment (Table I)}

Housing in different environments did not result in significant changes in SCN volume, cell density or cell number in either young or old rats. The same holds true for the rostrocaudal axis (length) and maximal cross-sectional area of the SCN. In the OE rats there was a tendency towards a smaller nuclear diameter (as stained by thionin), but it failed to reach the level of significance $(P=0.06)$. The stainability of the AVP cells was unchanged between the two housing conditions for both young $(P>0.30)$ and old rats $(P>0.31)$ and after pooling these age groups $(P>$ $0.24)$. Because differences in the various parameters between the rats housed in a standard or enriched condition were absent, the animals within one age group were pooled for subsequent analyses.

\section{Effects of aging (Table II)}

The SCN volume was about $13 \%$ larger in the old rats as compared with young rats. The rostrocaudal axis (length) did not appear to change with age, whereas the maximal cross-sectional area was significantly greater in the old group. Total cell density decreased significantly in senescence. The increased SCN volume and decreased cell density in old age resulted in an unchanged total cell number of the SCN, $26,000 \pm 800$ (mean \pm S.E.M.) at one side. The mean diameter and volume of the nuclei of the thionin-stained cells increased significantly in the old rats. 
The number of AVP cells decreased significantly with age by $31 \%(P=0.007)$. Following inclusion of the 3 animals in which the SCN was not properly stained, this difference appeared no longer to be significant $(P=0.094)$. The number of AVP cells in the SCN decreased from $4.3 \%$ to $3.1 \%$ of the total cell number, as calculated after exclusion of the 3 lowstaining animals. The cell diameter of the AVPstained neurons was increased in old age.

Negative correlations were found between number and diameter of AVP neurons $(r=-0.59, P=$ 0.003 ) as well as between AVP cell number and mean nucleus diameter of the thionin-stained cells $(r=$ $-0.58, P=0.004)$. After inclusion of the 3 non-stain- ing animals the first correlation still existed, but the last disappeared $(r=-0.22, P=0.15)$.

There appeared to be a slight reduction in stainability of the SCN with age, but it failed to reach significance as estimated by two independent investigators $(P=0.07$ and $P=0.06)$. The variability in staining intensity was indeed considerable within each age group.

AVP cell number did not correlate with the relative amplitude of the circadian sleep-wakefulness rhythm, as was taken from a separate study ${ }^{26}(r=$ $0.35, P=0.08)$. Significant but weak correlations were found between rapid-eye-movement (REM) sleep time and (a) AVP cell number $(r=0.53, P=$

\section{TABLE I}

Young rats in standard environment $(n=6)$ and enriched environment $(n=5)$; old rats in standard environment $(n=9)$ and enriched environment $(n=5)$

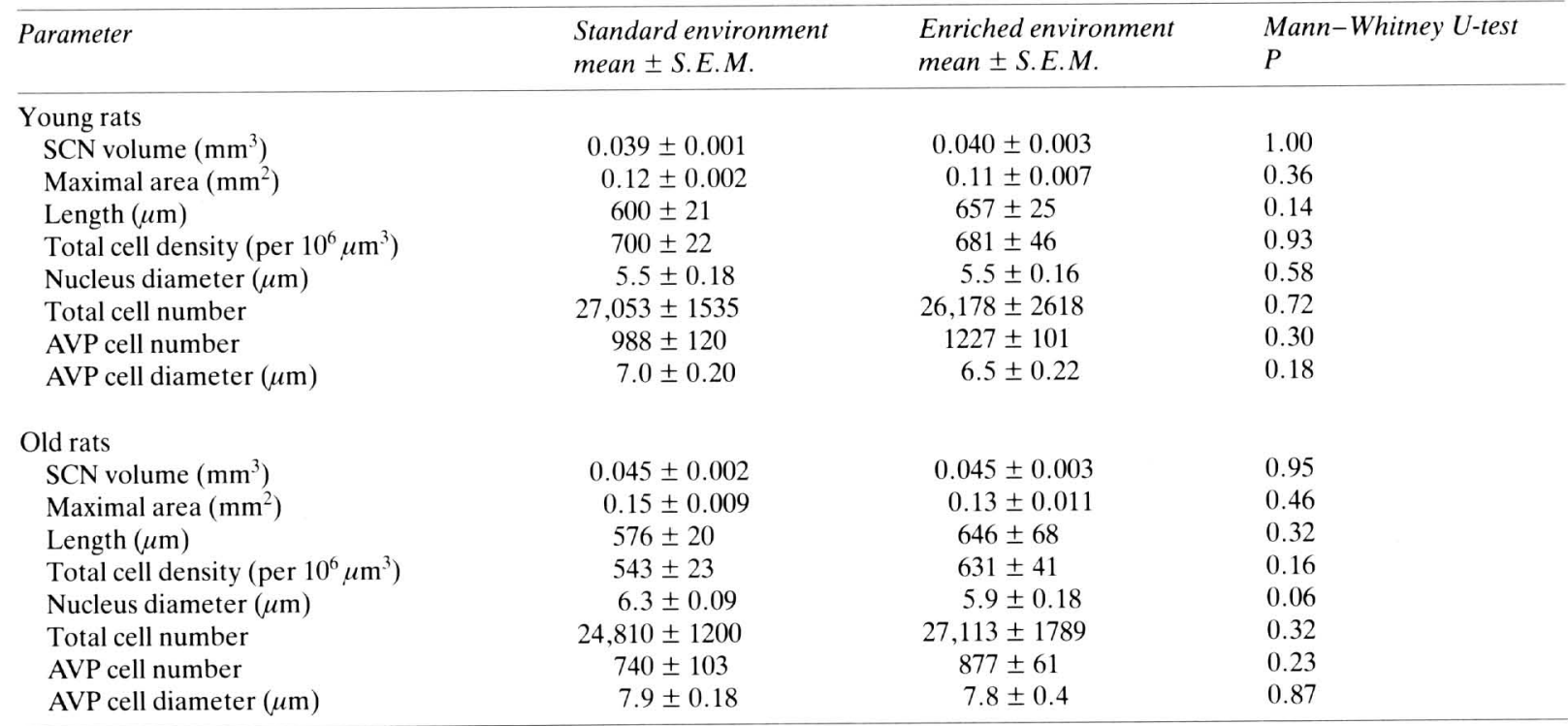

TABLE II

Effects of aging

\begin{tabular}{lccl}
\hline Parameter & $\begin{array}{c}\text { Young rats }(n=11) \\
\text { mean } \pm \text { S.E.M. }\end{array}$ & $\begin{array}{l}\text { Old rats }(n=14) \\
\text { mean } \pm \text { S.E.M. }\end{array}$ & $\begin{array}{l}\text { Mann-Whitney U-test } \\
P\end{array}$ \\
\hline SCN volume $\left(\mathrm{mm}^{3}\right)$ & $0.039 \pm 0.001$ & $0.045 \pm 0.002$ & $0.02^{*}$ \\
Maximal area $\left(\mathrm{mm}^{2}\right)$ & $0.11 \pm 0.004$ & $0.14 \pm 0.007$ & $0.004^{*}$ \\
Length $(\mu \mathrm{m})$ & $626 \pm 18$ & $601 \pm 28$ & 0.34 \\
Total cell density $\left(\right.$ per $\left.10^{6} \mu \mathrm{m}^{3}\right)$ & $691 \pm 23$ & $574 \pm 23$ & $0.006^{*}$ \\
Nucleus diameter $(\mu \mathrm{m})$ & $5.5 \pm 0.11$ & $6.2 \pm 0.10$ & $0.001^{*}$ \\
Total cel number & $26,655 \pm 1381$ & $25,632 \pm 1007$ & 0.41 \\
AVP cell number & $1137 \pm 84$ & $786 \pm 72$ & $0.007^{*}$ \\
AVP cell diameter $(\mu \mathrm{m})$ & $6.7 \pm 0.18$ & $7.8 \pm 0.17$ & $0.001^{*}$
\end{tabular}

* Statistically significant (Mann-Whitney, two-tailed and corrected for ties, $P=0.05$ ) difference between the young and old group. 
$0.01)$, (b) AVP cell diameter ( $r=0.43, P=0.04)$ and (c) nucleus diameter as measured in the conventionally stained material $(r=-0.56, P=0.003)$.

\section{DISCUSSION}

The data on SCN volume, rostrocaudal axis and total cell number of the present study agree generally with those reported in literature ${ }^{7,11,17,23}$. Minor differences may be attributed to differences in morphometric procedures or rat strain.

The absence of effects of differential housing upon the SCN is in accordance with lack of effect of the enriched environment upon circadian organization of sleep-wakefulness patterns both in YE and OE rats $^{26}$. A change in morphometric parameters of the SCN in these rats was therefore not expected and, as illustrated in Table I, not found in the present study.

Several changes were observed in the SCN in senescence. The enlargement of SCN volume in old age was mainly due to an increase in the maximal cross-sectional area, whereas the length of the rostrocaudal axis did not change. The rat SCN becomes consequently relatively more spherical in senescence.

Peng et al. ${ }^{17}$ reported that a reduction of the light/ dark ratio's of locomotor and consumatory behaviour was not accompanied by a change in SCN total cell number in senescent rats. Indeed, we found no reduction in total cell number in our aged animals although they exhibited significantly reduced light/ dark ratio's of sleep-wakefulness as compared to young rats in a separate study ${ }^{26}$. In thionin-stained material taken from old rats the cell density was less than that observed in young rats while the diameter of the cell was increased. These results agree with a study in Golgi-impregnated sections of the SCN in old mice ${ }^{12}$ in which $\mathrm{SCN}$ cell bodies were shown to swell. In addition, these authors reported that the dendrites of the neurons were thin, irregular and shortened, and that the dendrites did not bear spines. These observations suggest that functional changes in senescent circadian organization may be related to subtle morphological changes in SCN neurons, whereas the total cell number may still be constant. Also from observations in the human $\mathrm{SCN}$, it had to be concluded that functional alterations of circadian patterns precede cell loss in the SCN over an extended period of time ${ }^{20}$. A constant total SCN cell number does of course not preclude a decrease in neuron number that is compensated for by an increase in the number of glial cells. Gliosis in the senescent rat has been described in the neocorte $\mathrm{x}^{27}$ and the hippocampus ${ }^{10}$, but this possibility has not yet been investigated in the hypothalamus.

AVP has long been known to be a good marker for a subgroup of neurons within the $\mathrm{SCN}^{19}$. A reduction of approximately $31 \%$ was observed in SCN AVP cell number. Reduced counts of AVP cells may reflect either a loss of neurons or a reduced stainability because of reduced AVP content. The first possibility is supported by a morphometric study in human subjects, which revealed a dramatic loss of AVP neurons and total cell number in elderly subjects and even more in Alzheimer's disease ${ }^{20}$. However, since (1) the percentage of AVP cells in the SCN decreased in old rats, whereas (2) the total cell number did not change and (3) staining intensity of AVP neurons was slightly but not significantly reduced in old age, the decreased number of AVP cells might well be attributed to a reduced AVP content of these neurons. Such a reduced peptide content might be due to decreased metabolism in these neurons which in turn may precede cell death.

The AVP neurons in the SCN of old rats that do stain show an increased diameter as indicated in Table II. In other AVP-containing nuclei, i.e. the SON and the paraventricular nucleus $(\mathrm{PVN})$, increased cell size is correlated with enhanced peptide production (cf. refs. 4, 9, 28). Consequently, if cell size is also a proper parameter for peptide production in the SCN in old age, the remaining AVP neurons in the SCN seem to compensate for the loss of AVP neurons. The observation that a correlation exists in our material between AVP cell number at one side and AVP cell diameter and total nuclear diameter, at the other side, speaks in favour of this possibility. Alternatively, AVP neurons might increase in size in senium, e.g. by accumulating pigments ${ }^{13}$.

Since it was shown in the present study that changes may occur in AVP neurons in senescence, without affecting the total SCN cell number, it seems to be of interest to extend this study towards other subpopulations of neurons (e.g. VIP; 24), glial cells and innervating fibers (e.g. the cholinergic and sero- 
tonergic innervation) in order to determine what initial changes within the SCN might be associated with changes in circadian organization in senescence.

\section{ACKNOWLEDGEMENTS}

Part of this work was supported by the SOOM

\section{REFERENCES}

1 Brock, M.A., Biological clocks and aging, Rev. Biol. Res. Aging, 2 (1985) 445-462.

2 Card, J.P. and Moore, R.Y., The suprachiasmatic nucleus of the golden hamster: immunohistochemical analysis of cell and fiber distribution, Neuroscience, 13 (1984) $415-431$.

3 Cruz-Orive, L.M., Particle shape-size distributions: the general spheroid problem. II. Stochastic model and practical guide, J. Microsc., 112 (1978) 153-167.

4 Fliers, E., Swaab, D.F., Pool, C.W. and Verwer, R.W.H., The vasopressin and oxytocin neurons in the human supraoptic and paraventricular nucleus; changes with aging and in senile dementia, Brain Research, 342 (1985) 45-53.

5 Fliers, E., De Vries, G.J. and Swaab, D.F., Changes with aging in the vasopressin and oxytocin innervation of the rat brain, Brain Research, 348 (1985) 1-8.

6 Güldner, F.H., Synaptology of the rat suprachiasmatic nucleus, Cell Tissue Res., 165 (1976) 509-544.

7 Güldner, F.H., Numbers of neurons and astroglial cells in the suprachiasmatic nucleus of male and female rats, Exp. Brain Res., 50 (1983) 373-376.

8 Ingram, D.K., London, E.D. and Reynolds, M.A., Circadian rhythmicity and sleep: effects of aging in laboratory animals, Neurobiol. Aging, 3 (1982) 287-297.

9 Kalimo, H., Ultrastructural studies on the hypothalamic neurosecretory neurons of the rat, Cell Tissue Res., 163 (1975) 151-168.

10 Landfield, P.W., Baskin, R.K. and Pitler, T.A., Brain aging correlates: retardation by hormonal-pharmacological treatments, Science, 214 (1981) 581-584.

11 Lydic, R., Albers, H.E., Tepper, B. and Moore-Ede, M.G., Three dimensional structure of the mammalian suprachiasmatic nucleus: a comparative study of five species, J. Comp. Neurol., 204 (1982) 225-237.

12 Machado-Salas, J., Scheibel, M.E. and Scheibel, A.B., Morphological changes in the hypothalamus of the old mouse, Exp. Neurol., 20 (1977) 102-111.

13 Mann, D.M.A. and Yates, P.P., Lipoprotein pigments. Their relationship to ageing in the human nervous system, Part I, the lipofuscin content of nerve cells, Brain, 97 (1974) 481-488.

14 Miles, L.E. and Dement, W.C., Sleep and aging, Sleep, 3 (1980) 119-220.

15 Moore, R.Y., The anatomy of central neural mechanisms regulating endocrine rhythms. In D.T. Krieger (Ed.), Endocrine Rhythms, Raven, New York, 1979, pp. 63-88. (project 830804). We are grateful to Drs. E. Fliers and E. Goudsmit, and Mr. B. Fisser for his assistance in various aspects of this study. Dr. R. Baker's efforts to improve the English are appreciated.
16 Moore-Ede, M.C., Sulzman, F.M. and Fuller, C.A., The clocks that time us, Harvard University Press, Cambridge, 1982 , p. 16.

17 Peng, M.T., Jiang, M.J. and Hsü, H.K., Changes in running-wheel activity, eating and drinking and their day/night distributions throughout the lifespan of the rat, J. Gerontol., 35 (1980) 339-347.

18 Rusak, B. and Zucker, I., Neuronal regulation of circadian rhythms, Physiol. Rev., 59 (1979) 449-526.

19 Swaab, D.F., Pool, C.W. and Nijveldt, I., Immunofluorescence of vasopressin and oxytocin in the rat hypothalamoneurohypophyseal system, J. Neural Transm., 36 (1975) 195-215.

20 Swaab, D.F., Fliers, E. and Partiman, T.S., The suprachiasmatic nucleus of the human brain in relation to sex, age and senile dementia, Brain Research, 342 (1985) 37-44.

21 Ueda, S., Kawata, M. and Sano, Y., Identification of serotonin and vasopressin immunoreactivities in the suprachiasmatic nucleus of four mammalian species, Cell Tissue Res., 234 (1983) 237-248.

22 Van Eden, C.G., Uylings, H.B.M. and Van Pelt, J., Sex difference and left-right asymmetries in the prefrontal cortex during postnatal development in the rat, Dev. Brain Res., 12 (1983) 146-153.

23 Van den Pol, A.N., The hypothalamic suprachiasmatic nucleus of the rat: intrinsic anatomy, J. Comp. Neurol., 191 (1980) 661-702.

24 Van den Pol, A.N. and Tsujimoto, K.L., Neurotransmitters of the hypothalamic suprachiasmatic nucleus: immunocytochemical analysis of 25 neuronal antigens, Neuroscience, 15 (1985) 1049-1086.

25 Van Gool, W.A. and Mirmiran, M., Aging and Circadian Rhythms. In D.F. Swaab, E. Fliers, M. Mirmiran, W.A. Van Gool and F. van Maaren (Eds.), Aging of the Brain and Alzheimer's Disease, Progress in Brain Research, Vol. 70, Elsevier, Amsterdam, 1986, pp. 255-277.

26 Van Gool, W.A. and Mirmiran, M., Effects of aging and housing in an enriched environment on sleep-wake patterns of rats, Sleep, 9 (1986) 335-347.

27 Vaughan, D.W. and Peters, A., Neuroglial cells in the cerebral cortex of rats from young adulthood to old age: an electron microscope study, J. Neurocytol., 3 (1974) 405-429.

28 Zambrano, D. and De Robertis, E., The effects of castration upon the ultrastructure of the rat hypothalamus, part I, supraoptic and paraventricular nuclei, Z. Zellforsch. Mikrosk. Anat., 86 (1968) 487-549. 